\title{
Ocena mikrostruktury i wybranych własności mechanicznych złączy zgrzewanych wybuchowo po obróbce cieplnej
}

\author{
Evaluation of microstructure and selected mechanical \\ properties of explosive welded joints after heat treatment
}

\begin{abstract}
Streszczenie
W pracy przedstawiono wyniki oceny makro- i mikrostruktury złączy zgrzewanych wybuchowo poddanych obróbce cieplnej. Materiałem podstawowym do wykonania platerów była stal niestopowa P355NH, a materiałami nakładanymi były stale austenityczne $316 \mathrm{~L}$ i 254 SMO oraz stal superduplex SAF2507. Ocenie poddano mikrostrukturę stali podłoża oraz nakładanych powłok ze szczególnym uwzględnieniem miejsca połączenia. Badania przeprowadzono na zgładach metalograficznych w przekroju poprzecznym złącza z wykorzystaniem mikroskopii świetlnej. Dodatkowo, w celu określenia właściwości mechanicznych złączy wykonano pomiary twardości.
\end{abstract}

Słowa kluczowe: zgrzewane wybuchowe; mikrostruktura; właściwości mechaniczne; obróbka cieplna

\begin{abstract}
The paper presents results of macro- and microstructure evaluation of explosive welded joints after heat treatment. As the base plate was non-alloyed steel - P355NH. The cladder plate were two austenitic steels (316 L and 254SMO) and super duplex steel (SAF2507). The microstructure testing was carried out near to fusion line on the side of base plate and cladder plate. The evaluation was carried out in the cross sections of joints. To assess the mechanical properties changes before and after heat treatment, the hardness measurement was done.
\end{abstract}

Keywords: explosive welding; microstructure; mechanical properties; heat treatment

\section{Wstęp}

WstępTechnologia zgrzewania wybuchowego pozwala na łączenie ze sobą metali i ich stopów o różnych właściwościach fizycznych w tym nie wykazujących wspólnej rozpuszczalności lub tworzących kruche fazy międzymetaliczne. $W$ procesie zgrzewania wybuchowego uzyskiwane jest złącze o charakterystycznej falistej budowie w obszarze zgrzania. Ze względu na przebieg procesu, w tym silne odkształcenie plastyczne materiału nakładanego, obserwowane są zmiany właściwości mechanicznych i mikrostruktury przy linii zgrzania [1,3]. W wyniku zgrzewania wybuchowego w pobliżu złącza obserwowane jest umocnienie zgniotowe, co przekłada się na znaczny wzrost twardości w tym obszarze. W celu usunięcia powstałych naprężeń i efektu zgniotu stosuje się obróbkę cieplną platerów obejmującą wyżarzanie odprężające, rekrystalizujące lub normalizujące [2,3]. W przypadku złączy stali austenitycznych istotny jest odpowiedni dobór parametrów obróbki cieplnej w celu uniknięcia wydzielania się węglików po granicach ziarn mogących być przyczyną np. korozji międzykrystaliczna [2].

Do badań wykorzystano złącza zgrzewane stali niestopowej ze stalami stopowymi poddane obróbce cieplnej. Badania obejmowały ocenę mikrostruktury i wybranych właściwości mechanicznych.

\section{Metodyka badań}

Do badań wykorzystano złącza zgrzewane stali niestopowej P355NH (materiał podłoża) i stali 316L, SAF2507, 254SMO. Składy chemiczne materiałów podłoża i nakładanych przedstawiono odpowiednio w tablicy I i II. Złącza zostały wykonano w Zakładzie Technologii Wysokoenergetycznych EXPLOMET Gałka Szulc Sp. J. Opola. Próbki do badań oznaczono: $x / 1, x / 2, x / 3$, gdzie $x$ to numer odpowiadający danemu materiałowi nakładanemu, a odpowiednio 1 oznacza próbkę bez obróbki cielnej, 2 po obróbce cieplnej w temperaturze $610^{\circ} \mathrm{C}$ przez 90 min, i 3 po obróbce cieplnej w temp. $910^{\circ} \mathrm{C}$ przez $30 \mathrm{~min}$. Materiały nakładane mają przyporządkowaną następującą numerację: 2 - stal SAF2507, 4 - stal 254SMO, 5 - stal 316L. Złącza zgrzewane poddane zostały badaniom ultradźwiękowym, które nie ujawniły występowania wad zgrzein.

Obserwacje makro- i mikrostruktury wykonano przy wykorzystaniu mikroskopii świetlnej Obserwacje przeprowadzono na zgładach metalograficznych szlifowanych i trawionych. Właściwości mechaniczne oceniano w oparciu o pomiary twardości metodą Vickersa przy obciążeniu wgłębnika 0,5 kG (HV0,5). Odciski wykonano w odstępach co $0,2 \mathrm{~mm}$, po 10 odcisków w materiale nakładanym i podstawowym.

Inż. Natalia Pocica; dr inż. Lechosław Tuz - AGH Akademia Górniczo-Hutnicza w Krakowie.

Autor korespondencyjny/Corresponding author. npocica@gmail.com 
Tablica I. Skład chemiczny materiału podłoża

Table I. Chemical composition of the base metal

\begin{tabular}{|c|c|c|c|c|c|c|c|c|c|c|}
\hline \multirow[t]{2}{*}{ Gatunek } & \multicolumn{10}{|c|}{ Skład chemiczny \% } \\
\hline & C & Si & $\mathrm{Mn}$ & $\mathrm{P}$ & $S$ & $\mathrm{~N}$ & $\mathrm{Al}$ & $\mathrm{Cu}$ & $\mathrm{Cr}$ & $\mathrm{Ni}$ \\
\hline \multirow{3}{*}{ P355NH } & 0,18 & 0,33 & 1,23 & 0,012 & 0,001 & 0,003 & 0,038 & 0,19 & 0,03 & 0,21 \\
\hline & Mo & $\mathrm{V}$ & $\mathrm{Ti}$ & $\mathrm{Nb}$ & *EV1 & **EV2 & B & $\mathrm{Fe}$ & & \\
\hline & 0,003 & 0,003 & 0,003 & 0,02 & 0,03 & 0,42 & 0,0003 & reszta & & \\
\hline
\end{tabular}

Tablica II. Skład chemiczny materiałów nakładanych

Table II. Chemical composition of the coat metals

\begin{tabular}{|c|c|c|c|c|c|c|c|c|c|c|c|c|c|}
\hline \multirow{2}{*}{ Gatunek } & \multicolumn{13}{|c|}{ Skład chemiczny \% } \\
\hline & C & $\mathrm{Si}$ & Mn & $\mathbf{P}$ & S & $\mathrm{Cr}$ & $\mathrm{Ni}$ & Mo & $\mathrm{Cu}$ & Al & N & $\mathrm{Nb}$ & $\mathrm{Fe}$ \\
\hline SAF2507 & 0,015 & 0,37 & 0,83 & 0,026 & 0,001 & 24,9 & 6,86 & 3,79 & 0,33 & - & 0,25 & - & reszta \\
\hline 254SMO & 0,014 & 0,39 & 0,38 & 0,021 & 0,001 & 19,99 & 17,96 & 6,05 & - & - & - & 0,012 & reszta \\
\hline $316 \mathrm{~L}$ & 0,024 & 0,420 & 1,510 & 0,024 & 0,002 & 16,9 & 10,0 & 2,010 & - & 0,010 & 0,40 & - & reszta \\
\hline
\end{tabular}

\section{Wyniki badań $\mathrm{i}$ ich analiza}

Makro- i mikrostruktura złącza

We wszystkich badanych próbkach zaobserwowano falisty charakter połączenia w miejscu zgrzania. Ujawniono występowanie niewielkiej ilości przetopień, których występowanie uzależnić można od parametrów procesu.

W złączach przed obróbką cieplną ujawniono strukturę ferrytyczno-perlityczną materiału podłoża z silnie odkształconymi ziarnami w pobliżu linii zgrzania. Oddalając się od linii zgrzania występuje struktura ferrytyczno-perlityczna z ułożonymi naprzemiennie pasmami ferrytu i perlitu. Ziarna w tym obszarze nie uległy odkształceniu plastycznemu na skutek procesu zgrzewania (struktura po walcowaniu). Silnie odkształcone ziarna obserwowane są również po stronie materiału nakładanego (rys. 1). W przypadku tych materiałów również oddalając się od linii zgrzania silne odkształcenie zanika. Widoczne jest efekt bliźniakowania - bliźniaki wyżarzania (obecne przed zgrzewaniem i powstałe na skutek wysokiej temperatury procesu) i nowo powstałe bliźniaki mechaniczne (powstałe na skutek odkształcenia plastycznego nakładanej blachy). Ferrytyczno-austenityczna struktura stali superduplex uległa dużemu zniekształceniu przy linii zgrzania (rys. 2).

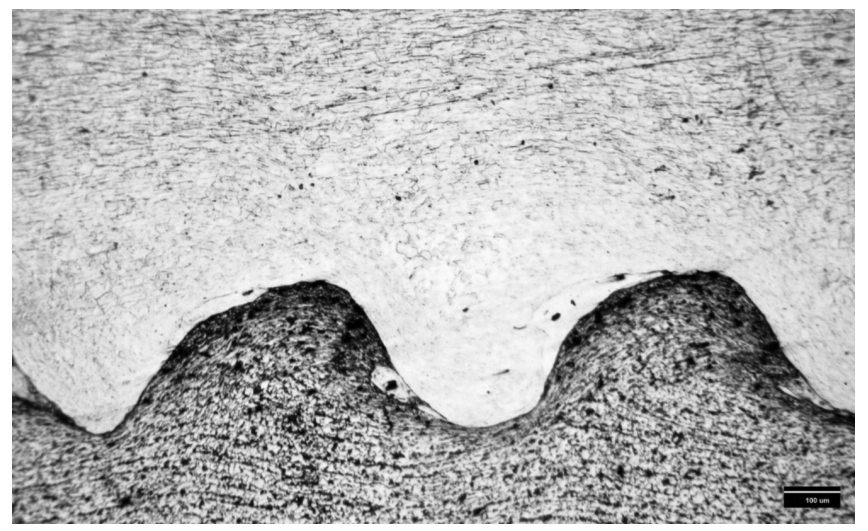

Rys. 1. Struktura złącza P355NH-316L bez obróbki cieplnej

Fig. 1. Structure of P355NH-316L explosive welded joint without heat treatment

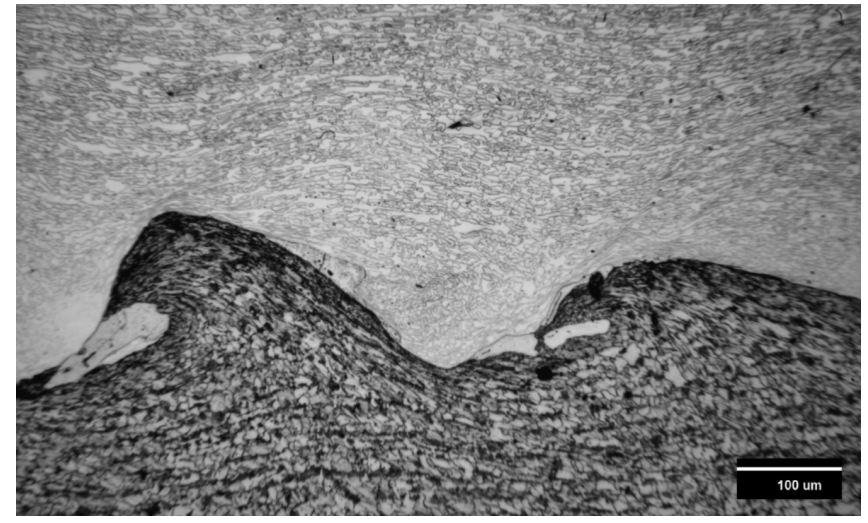

Rys. 2. Struktura złącza P355NH-SAF2507 bez obróbki cieplnej Fig. 2. Structure of P355NH-SAF2507 explosive welded joint without heat treatment

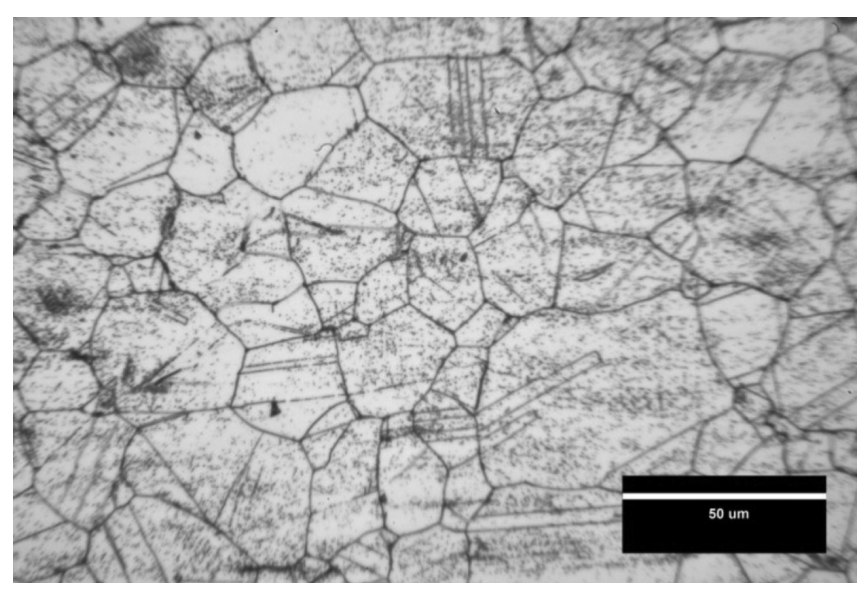

Rys. 3. Struktura stali 254 SMO

Fig. 3. Structure of $254 \mathrm{SMO}$ steel

W przypadku stali $316 \mathrm{~L}$ oraz 254SMO zaobserwowano silnie odkształcone ziarna austenitu w pobliżu złącza. Uwidoczniono również liczne pasma poślizgu oraz bliźniaki odkształcenia wynikające z umocnienia zgniotem (rys. 3).

Zastosowana obróbka cieplna w temp. $610{ }^{\circ} \mathrm{C}$ przez 90 min nie wpłynęła znacząco na zmiany w strukturze każdej z trzech badanych próbek (rys. $4 \div 6$ ). Nie zaobserwowano 
w żadnej z badanych stali rozrostu ziarna. Wskazuje to, że podczas obróbki cieplnej nie została przekroczona temperatura rekrystalizacji. Nie został usunięty również efekt umocnienia zgniotowego. Potwierdzają to wyniki pomiarów twardości, które są porównywalne do wyników otrzymanych dla próbek nieobrobionych cieplnie.

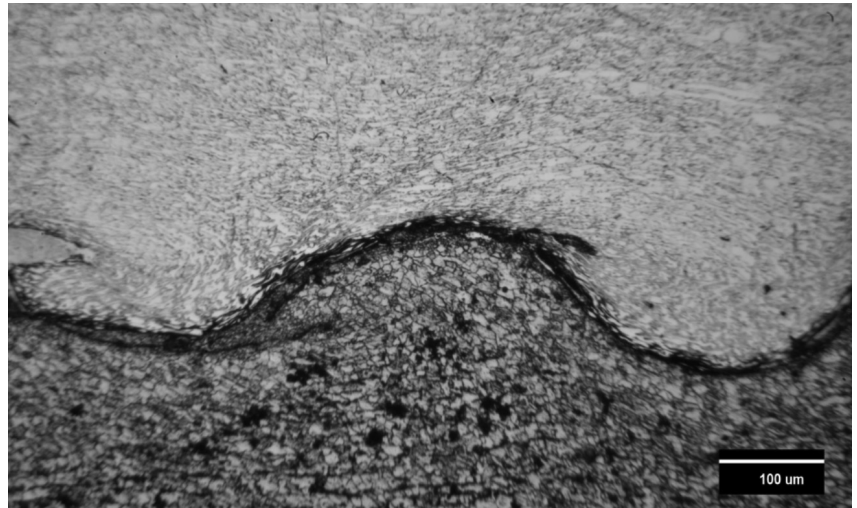

Rys. 4. Struktura złącza P355NH-SAF2507 po obróbce w temp. $610^{\circ} \mathrm{C}$ przez $90 \mathrm{~min}$.

Fig. 4. Structure of P355NH-SAF2507 explosive welded joint after heat treatment: $610^{\circ} \mathrm{C} / 90 \mathrm{~min}$.

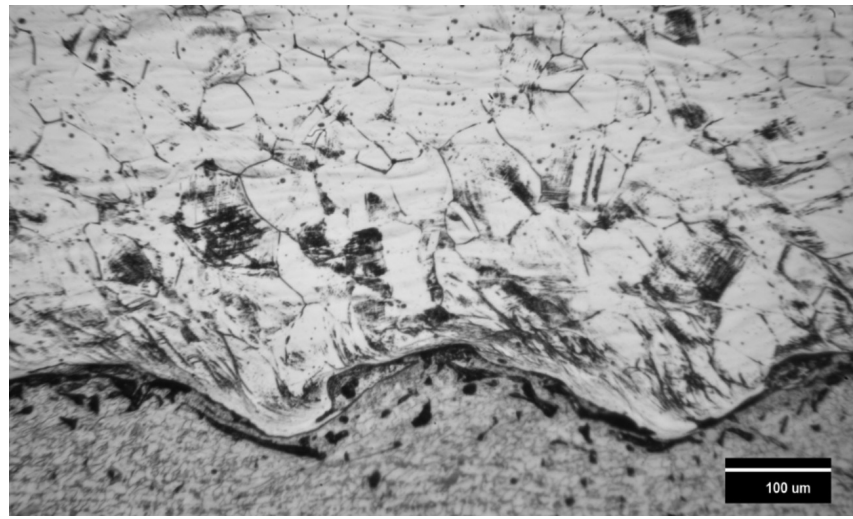

Rys. 5. Struktura złącza P355NH-254SMO po obróbce cieplnej w temp. $610^{\circ} \mathrm{C}$ przez $90 \mathrm{~min}$.

Fig. 5. Structure of $\mathrm{P} 355 \mathrm{NH}-254 \mathrm{SMO}$ explosive welded joint after heat treatment: $610^{\circ} \mathrm{C} / 90 \mathrm{~min}$.

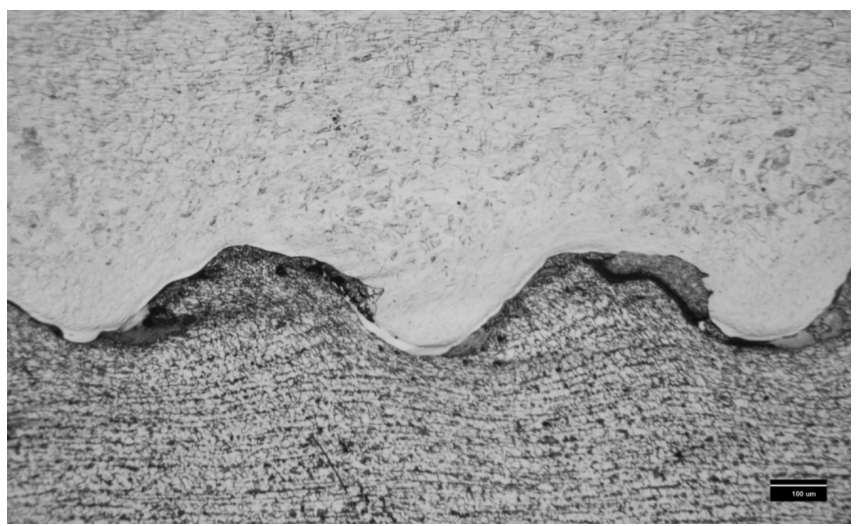

Rys. 6. Struktura złącza P355NH-316L po obróbce cieplnej w temp. $610^{\circ} \mathrm{C}$ przez $90 \mathrm{~min}$

Fig. 6. Structure of $\mathrm{P} 355 \mathrm{NH}-316 \mathrm{~L}$ explosive welded joint after heat treatment: $610^{\circ} \mathrm{C} / 90 \mathrm{~min}$.

Obróbka cieplna platerów w temp. $910{ }^{\circ} \mathrm{C}$ przez 30 min spowodowała odwęglenie stali P355NH w pobliżu linii złącza dla każdej z badanych próbek (rys. 7 i 8). Występuje głównie ferryt z niewielką ilością perlitu. Zaobserwowano również rozrost ziaren ferrytu w materiale podstawowym oraz rozrost ziaren austenitu w materiale nakładanym, co jest wynikiem procesu rekrystalizacji. Zmiany struktury w złączach potwierdzają pomiary twardości, która znacznie spadła w obszarze złącza co świadczy o tym, że efekt zgniotu został usunięty.

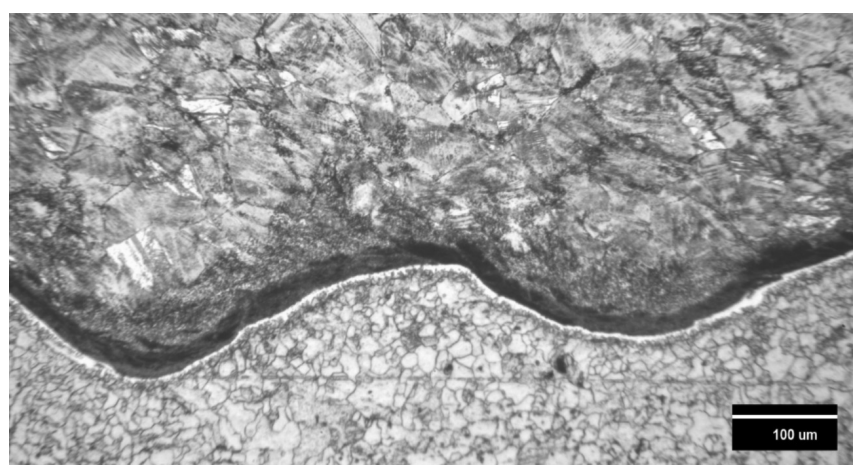

Rys. 7. Struktura złącza P355NH-254SMO po obróbce cieplnej w temp. $910^{\circ} \mathrm{C} / 30 \mathrm{~min}$.

Fig. 7. Structure of $\mathrm{P} 355 \mathrm{NH}-254 \mathrm{SMO}$ explosive welded joint after heat treatment: $910^{\circ} \mathrm{C} / 30 \mathrm{~min}$.

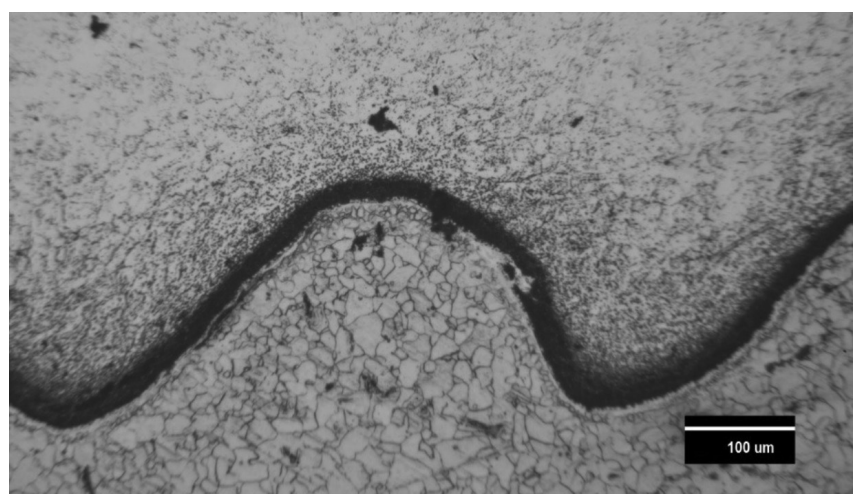

Rys. 8. Struktura złącza P355NH-316L po obróbce cieplnej w temp. $910^{\circ} \mathrm{C} / 30 \mathrm{~min}$.

Fig. 8. Structure of $\mathrm{P} 355 \mathrm{NH}-316 \mathrm{~L}$ explosive welded joint after heat treatment: $910{ }^{\circ} \mathrm{C} / 30 \mathrm{~min}$.

Wykonane pomiary ujawniły nieznaczny wzrost twardości o ok. 30 $\div 50$ HV0,5 w materiale podstawowym (stal P355NH) w wyniku procesu zgrzewania. Obszar o podwyższonej twardości sięga ok. 0,4 $\div 0,8 \mathrm{~mm}$ od linii zgrzania. Podobny efekt wzrostu twardości zaobserwowano również w platerach - najsilniejszy w stali 316L (o ok. 150 HV0,5), a najmniejszy w stali SAF2507. Zastosowana obróbka w OC2 $\left(910{ }^{\circ} \mathrm{C} / 30\right.$ min) spowodowała spadek twardości zarówno metali podłoża jak i platerów austenitycznych. W przypadku stali 316L obserwowana jest najmniejsza różnica twardości pomiędzy podłożem i platerem. Obróbka cieplna OC1 $\left(610{ }^{\circ} \mathrm{C} / 90 \mathrm{~min}\right)$ nie wpływa znacząco na zmianę twardości.

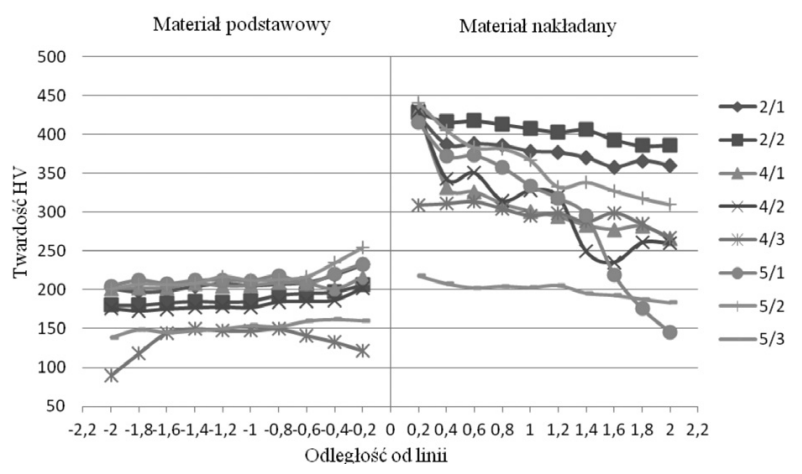

Rys. 9. Rozkład twardości w badanych złączach

Fig. 9. Hardness distribution in the analysed explosive welded joints 


\section{Wnioski}

Przeprowadzone badania pozwalają na sformułowanie następujących wniosków:

1. Technologia zgrzewania wybuchowego powoduje znaczne odkształcenie materiałów łączonych w pobliżu linii zgrzania,

2. Obróbka cieplna platerów $\mathrm{w}$ temp. $610^{\circ} \mathrm{C}$ nie powoduje zmian strukturalnych w materiale podstawowym i nakładanym i nie wpływa na obniżenie efektu umocnienia zgniotowego.

3. W wyniku obróbki w temp. $910{ }^{\circ} \mathrm{C} / 30$ min. obserwuje się spadek właściwości mechanicznych zarówno w materiale podstawowym, jak i nakładanym.

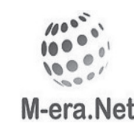

$$
\begin{gathered}
\text { Praca powstała z wykorzystaniem części badań prowadzonych } \\
\text { w ramach programu M-Era.net }
\end{gathered}
$$
„Nowe, odporne korozyjnie materiały wytworzone metodą wybuchową

M-era.Net

$$
\text { dla zastosowań w instalacjach geotermalnych".; }
$$

ExploGuard współfinansowany z środków NCBiR decyzją numer DZP/M-ERA.NET-2013/2309/2014.

\section{Literatura}

[1] Babul W., 1980: Odkształcenie metali wybuchem. Wyd. Naukowo - Techniczne, Warszawa.

[2] Pocica A., Bański R., Waindok P., Szulc Z., Gałka A., 2008: Wpływ czasu obróbki cieplnej na własności bimetalu tytan-stal. XVI Międzynarodowa Konferencja „Spawanie w energetyce”. Opole-Jarnołtówek 23-25 kwietnia 2008, Opole.
[3] Walczak W., 1989: Zgrzewanie wybuchowe metali i jego zastosowanie. Wydawnictwo Naukowo-Techniczne, Warszawa. 